\title{
The Impact of Value, Employees Performance and the Integration of Healthcare Services on Loyalty toward Community Pharmacies in Saudi Arabia: A Structural Model
}

\author{
Karim Garrouch ${ }^{1} \&$ Abdullah Alshemas ${ }^{1}$ \\ ${ }^{1}$ College of Administrative and Financial Sciences, Saudi Electronic University, Riyadh, Saudi Arabia \\ Correspondence: Abubakr Alseedik, Saudi Electronic University, P. O.BOX 93499, Riyadh 11673, Saudi Arabia. \\ E-mail: Kgarrouch@Seu.edu.sa
}

Received: April 10, 2021

Accepted: May 26, 2021

Online Published: June 17, 2021

doi:10.5539/ijbm.v16n7p80

URL: https://doi.org/10.5539/ijbm.v16n7p80

\begin{abstract}
With the focus of the scholars and literature on the importance of customer value, the emphasis has been paid to this concept in a great number of retailing specialties, but it was neglected in the case of community pharmacies. This research focuses on the service value, trust and employee performance as factors explaining loyalty to pharmacies and adds the verification of the impact of the integration of primary healthcare services as a way to enhance or sustain the level of loyalty to the initial pharmacy or switching intentions toward other pharmacies which integrate this kind of service. Thus, an original conceptual model is proposed and tested. A survey was distributed electronically via a social media application (WhatsApp) to participants based on the convenience sampling technique. 492 respondents submitted the survey. Results show that perceived value, employee performance and trust influence initial loyalty. In addition, the integration of Primary Healthcare services sustains this loyalty, but initial loyalty does not prevent switching intentions in case other pharmacies integrate primary healthcare services.
\end{abstract}

Keywords: primary healthcare service, pharmacy, loyalty, perceived value, trust, retailing

\section{Introduction}

The important role that the community pharmacy plays is increasingly recognized (Fathelrahman et al, 2016). Its main mission is to dispense medications to the community members, but it is also considered as "the first point of call" for people who seek advice for slight sickness self-care treatments. The Primary Healthcare service is a promising activity which can be integrated in community pharmacy services, but it needs to be backed-up by an improvement of public perception (Martínez-Mardones et al., 2020). The Saudi Arabia vision 2030 highlights the importance of primary healthcare, stating that it serves as the cornerstone of a strong healthcare system. It also underscores the immense benefits that primary health care has on the health of people. Community pharmacy provides basic services such as drug retailing and can extend this activity to providing primary healthcare services (PHCS) such as blood pressure checking and treatment of non-serious diseases or injuries. Although PHCS is a new concept in community pharmacy, its implementation has not been without challenge across the world. There exist studies such as those that have highlighted the importance of primary health care services, while in Saudi Arabia no studies have been done on this concept in the case of community pharmacies, as this is still not applied in the Saudi market. Particularly, there exists little literature on the impact of primary health care services (PHCS) provided by community pharmacies on customer behavior. Community pharmacies with PHCS may impact the relationship that exists between the customers and the service providers, namely pharmacies. The adoption of PHCS by pharmacy owners aims to add value to community patients/customers and to meet their requirements in order to enhance loyalty within the community. The pharmacists frequently work as forefront workers and their capacity is very crucial due to the nature of the job and customer requirements. As far as we know, there is no scientific attempt to verify the impact of a possible integration of PHCS on consumer-pharmacy relationship.

The purpose of this research is to study the predictor of customers' loyalty toward the community pharmacy and establish the importance of adding PHCS as a way to enhance the loyalty toward the pharmacy.

First, it is interesting to present a literature review of the most important elements leading patients and customers to be loyal to a pharmacy. As the products and prices are mostly similar between pharmacies, the main variables 
leading to prefer a pharmacy among others would be the interpersonal service quality, mainly related to the employee performance, the trust toward the pharmacy as it has an advising role. Perceived value is also important in any service but not yet verified in the community pharmacies case. The theoretical background of these variables is based on a literature review which led to find the frameworks of Rabbanee et al (2015) and Wongleedee (2020) applied to the pharmacy sector. We adapt his model and extend it by focusing on the impact of the integration of PHCS.

This study has potential theoretical and practical implications. The former stems mainly from the originality of splitting loyalty into two phases, the Initial loyalty, and the expected loyalty after the integration of PHCS. We also add the idea of switching intention if PHCS is integrated by the pharmacy's competitor. The latter is related first to highlighting the important predictors of loyalty to community pharmacies. Another managerial interest of this research is about presenting the integration of simple services as a way to enhance the initial loyalty and avoid switching behaviors.

\section{Literature review}

\subsection{Loyalty and Switching Intention.}

Castaldo et al (2016) explain the lack of studies on loyalty toward pharmacies by the fact that these are mainly viewed as drug dispensers. Zeithaml et al. (1996) consider that loyalty is characterized by positive behaviors regarding a provider. These behaviors may be attitudinal including the preference for a brand or a provider, intention to buy or repurchase a product, word-of-mouth... Loyalty is also defined as a profound "commitment to rebuy or re-patronize a preferred product/service consistently in the future ..." (Oliver. 1999. p. 34). Molinillo et al (2021) argued that customer loyalty intention is a one-dimensional construct that captures customers' intentions to repurchase and recommend.

Prior studies have indicated that loyalty can be associated with various concepts reflecting the relationship between consumers and a company or a type of commerce. These concepts include engagement (Shawky et al., 2020), commitment, stickiness intention (Molinillo et al., 2021) and long-term psychological connection (Xue et al., 2020).

Loyalty has a great importance for commercial success, and it is generally identified that it is in line with the longterm goals of any business, via the retention of customers (AlRefaie, 2015; Molinillo et al, 2021). Behavioral loyalty corresponds to apparent consumer characteristics like the shopping frequency at a pharmacy, while attitudinal loyalty refers to the perception that the customer has on the facility based on the past shopping behaviors. In this study, the authors define loyalty toward the pharmacy in two ways:

- The loyalty toward the initial community pharmacy: this loyalty is already existing; it concerns the loyalty toward the community pharmacy that the customer is used to deal with. This pharmacy provides only basic services, such as medications, cosmetics, and health products.

- Post loyalty: It is the expected loyalty toward the same pharmacy if it includes PHCS in the future.

Service switching is a significant research topic because preventing the possibility of client-switching from a service provider to another is a sensitive and challenging task (Quoquab et al. 2018; Thaichon and Jebarajakirthy, 2016). Quoquab et al (2018) present it in a mobile service context as a situation where users intend to switch from an actual service provider to another. The term switch relates to the customer changing their current engagement and relationship with their current service provider and in all likely manner change to the services offered by the competitor in the market.

The idea of switching would come to consumers because they do not bear poor or lacking services. Thus, perceived service quality inferiority compared to other service providers or degradation of this quality would lead to service switching (Quoquab et al. 2018). Complete switching occurs when the customer has lost all the interest in the pharmacy and will not be able to come even for any service within the facility. Provider Switching is generally associated with switching costs and the availability of a better option (competitors are more attractive).

Quoquab et al (2018) explain this relationship by the expectancy-disconfirmation paradigm. Indeed, switching intention decreases when the outputs outperform expectations and increases when actual services are below prior expectations.

As the introduction of new service is hypothetical, we cannot link perceived quality to possible switching intentions to other pharmacies. Rather we will verify if the actual loyalty to the pharmacy will not prevent this switching intention if other pharmacies include the PHCS to their services.

Switching intention refers to the possibility that exists for a given customer to switch brands and choose the 
services of the other service provider in the market and is used to provide an organization an indication of whether a given customer wants to change or stay within the organization or if the customer wants to change and defect. If the service that is given by another service provider is convenient and serve the best interest of the individual, then the switching intention can occur and loyalty diminished (Meesala \& Paul, 2018; Gupta \& Rokade, 2016).

We expect that an initial loyalty level with a pharmacy will have a positive impact on the level of loyalty after adding a new service (post loyalty), namely the PHCS. Moreover, it will reduce of the impact of switching to other pharmacies that integrate that new services. The idea is that the pharmacy should have created a high level of loyalty to enhance the post loyalty and to hamper post switching intentions if the pharmacy is late to install this new service while other competitors are fast to integrate it.

H1- Initial loyalty has a positive impact on Post loyalty if PHCS is integrated by the pharmacy.

H2- Initial loyalty has a negative impact on Post switching intention to other pharmacies including PHCS.

\subsection{Determinants of Loyalty}

\subsubsection{Employees Performance}

In many services, the performance of employees when interacting with customers is significant as a determinant of the organization's success. Researchers have been able to emphasize the importance of employee performance in service workplaces (Worlu et al., 2016; Wang et al, 2017; Rabbanee et al, 2015). Rabbanee et al (2015) present employee performance as the set employee behaviors in relevance with the company's goals, namely the pharmacy goals. It is a part of service quality as perception of service quality is mainly formed by their perception of employee behavior. Rabbanee et al (2015) found that employees play a key role in pharmacies and that this role is even higher in importance compared to the one played by other retail stores' employees. Indeed, pharmacists are frontline employees having delicate and critical tasks because of the specificities of their job (combining expert health services with selling tasks) and the special customer demand. The latter involves expertise in health consultation and appropriate emotion sharing at some point in the process of the service transaction (Rabbanee et al, 2015).

Dwivedi (2015) establishes that greater customer satisfaction in the organization can be reached at and achieved through the putting in place improvements made by the organization that would be able to ensure that there exists proficiency, the efficiency of service and engagement through service quality. Thus, the employees play a very crucial role in the organization performance. Meesala \& Paul. (2018) established the fact that employee performance plays a decisive role in customer loyalty and perception of service value. The display of numerous behavior by employees enhances the perception of quality service by the customers. The non-technical perspective in measuring employee performance refers to the strengths and the frequency of smiling to the customers, establishing eye contact, greeting the customer and being kind and helpful to the customer (Meesala \& Paul. 2018).

AlRefaie (2015) identifies that customer loyalty is further influenced by service quality, customer expectation and whether this is met, price strategy and product quality. Gupta \& Rokade, (2016) identify that pharmacists need to understand what the customers want for them to provide service quality. Further, AlRefaie, (2015) identifies that customers would usually access the quality of service based on perception.

The higher the level of performance by the employees of a given brand of the company would have a high influence on the loyalty levels. When employees are engaged and perform their duties well in the pharmacy, then the customers are bound to be satisfied and thus will go and come back again for the same service at the pharmacy. Indeed, Wang et al. (2017) verify the influence of service excellence, which is mainly associated with employee performance, on the store revisit likelihood and store recommendation.

Jung et al (2021) focus on the interactive facet of retailing contexts, where retail employees have a key role in creating value. They assert that employee attitudes are among the determinants of customer attitudinal and behavioral responses, namely customer brand equity, and loyalty. This assumption is justified by the fact that contact employees are able to deliver excellent service and thereby, can influence customer loyalty. Accordingly,

H3: Employees Performance has a Positive Impact on Loyalty toward community Pharmacy.

\subsubsection{Perceived Value}

Value has a strategic significance as it is a basis of competitive advantages (Song et al, 2019; Woodruff, 1997). In an administrative perspective applied to pharmacies, pharmacy value refers to attaining quality objectives simultaneously with a reduction or stabilization of healthcare spending. It may also aim at reducing healthcare costs while stabilizing or enhancing quality levels (Urick and Urmie, 2019).

At the conceptual level, Castaldo et al. (2016) assert that the perception of value is a customer's cognition that is 
based on relational exchanges that such have made with the service providers. Perceived value is an outcome of the tradeoff between benefits and costs perceived by customers after (or during) the purchase or consumption of a good or a service (Graciola et al, 2020; Zeithaml, 1988; Worlu et al., 2016). This definition is considered in a perspective assuming customers as rational economic people who always ask for maximum return with minimum efforts (Song et al, 2019). Accordingly, our study considers that value perception is an overall assessment made by pharmacy clients regarding the pharmacy services, based on perceived benefits and sacrifices.

Marketing literature proposes a value model where perceived value influences directly the customer loyalty (Sweeney et al., 1999). Worlu et al (2016) consider that this concept is simply an instant factor explaining repurchase intentions. Indeed, customers tend to repurchase goods or services from the provider who offers a higher value for the money spent (Molinillo et al, 2021; Garrouch, 2021a, b)

Recent studies confirmed that perceived value increases continuance intentions or loyalty with service providers in general (Molinillo et al, 2021; Garrouch, 2021a; Garrouch et al., 2020, 2012), and particularly in healthcare services (Worlu et al. 2016, Wu et al, 2016; Rabbanee et al, 2015). Accordingly,

H4: Perceived value have a positive impact on Loyalty toward the Initial Community Pharmacy.

\subsubsection{Trust}

Trust is amongst the determining factors of and behavior intentions loyalty in many services (Garrouch and Timoulali, 2020; Berry, 2016; AlRefaie, 2015; Mayer et al., 1995). According to Morgan and Hunt (1994) trust is a certain degree of confidence of one party of an exchange toward another party's integrity and reliability. This confidence is assessed as the willingness of the trustor to put oneself in a situation of vulnerability to possible actions of the trustee because the former expects that the latter will have the ability and motivation to act according to the trustor's interest and expectations (Mayer et al., 1995).

Customer conviction plays an essential role as the pharmacies need to improve patients' (i.e., buyers') trust. This is influenced by appropriate counseling from the pharmacist (Perepelkin, and Di Zhang, 2011) and by factors related to operational facets of a community pharmacies and their staff . According to AlRefaie, (2015), the failure by the pharmacist to understand the expectations of the patient and the requirements that he or she wants from the healthcare facility would result in customer losing trust in the facility.

In this research we focus on the trust toward the pharmacy as per the perception of its customers. In a consumer perspective, trusting clients generally believe in the ability of the organization (pharmacy) and its employees as well as their motivation to meet the quality expectations. Rabbanee et al (2015) focus on the pharmacy context and asserts that trust in community pharmacies is two-dimensional as it has a cognitive and an affective facets.

Most of the customers of a healthcare facility might usually not identify the underlying elements of the treatment process. They are not able to ascertain whether the services have been carried in the right manner or not as they have little knowledge of the medical and the pharmaceutical processes. Thus, the trust that they have in the is what drives them to maintain and attain confidence on the facility and to further develop loyalty. Accordingly, Gwinner et al. (1998) maintained that trust is among the psychological benefits that are important than in the customerprovider relationship. Patients have obviously higher expectations regarding healthcare services, compared to other sectors (Lee, 2021)

In a healthcare service context, Torres et al. (2009) suggested that trust influences patients' loyalty. Castaldo et al (2016) verified the impact of two trust perspectives on loyalty toward pharmacies: trust in pharmacist and trust in pharmacy. They verified that the former has an impact on the latter, which in turn has a significant impact of loyalty.

H5: Trust Has a Positive Impact on Loyalty Toward the Initial Community Pharmacy.

The Model summarizing previous hypotheses is displayed in Figure 1: 


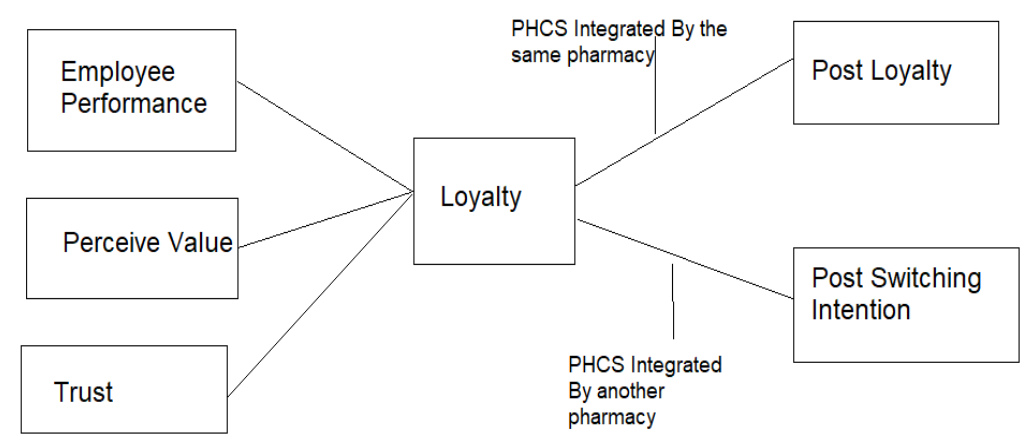

Figure 1. Conceptual model

\section{Research Methodology}

\subsection{Design and Sample}

A survey was distributed electronically via a social media application (WhatsApp) to participants from the public based on the convenience sampling technique. 492 respondents submitted the survey. The survey has two sections. The first part measured the loyalty toward the community pharmacy that the responded have recently visited. After, answering all items, the respondent is introduced to the idea of integrating PHCS in this or other pharmacies. After this introduction of the idea, the sample have answered to items measuring two variables:

- $\quad$ The possible loyalty to the pharmacy if it includes PHCS

- $\quad$ The possible switching intention to other pharmacies which exclusively include PHCS

Table 1 shows the respondents demographic information:

Table 1. Respondent's Demographic Information

\begin{tabular}{llll}
\hline Variables & Classification & Count & Percentage \% \\
\hline \multirow{2}{*}{ Gender } & Male & 304 & $61.8 \%$ \\
& Female & 188 & $38.2 \%$ \\
Age & Less than 18 & 6 & $1.2 \%$ \\
& $18-30$ & 182 & $37 \%$ \\
& $31-40$ & 157 & $31.9 \%$ \\
Nationality & $41-50$ & 68 & $13.8 \%$ \\
& More than 51 & 79 & $16.1 \%$ \\
& Saudi & 469 & $95.3 \%$ \\
Monthly income & Non-Saudi & 23 & $4.7 \%$ \\
& Less than 4000 SR & 74 & $15 \%$ \\
& 5000-10,000 SR & 81 & $16.5 \%$ \\
& $10,000-15,000$ SR & 118 & $24 \%$ \\
& $15,000-30,000$ SR & 148 & $30.1 \%$ \\
Level of education & More than 30,000 SR & 71 & $14.4 \%$ \\
& Ph.D. & 18 & $3.7 \%$ \\
& Master & 89 & $18.1 \%$ \\
& Bachelor & 309 & $62.8 \%$ \\
& High school & 70 & $14.2 \%$ \\
& Less than high school & 6 & $1.2 \%$ \\
\hline
\end{tabular}

The majority of responses from a males' respondents $(61.8 \%)$ but the sample includes a respectable number of female subjects (188). Data were analyzed via SMARP-PLS software.

\subsection{Measurements and Data Analysis}

All measurement items are borrowed from prior published articles except the switching intention which is built via a brainstorming between experts in marketing and pharmaceutical. 
Perceived value was measured with the scale of Yang and Peterson (2004) and adapted to the pharmacy context By Rabbanee et al (2015). The employee performance scale is measured via the scale of Salanova et al. (2005). Trust is assessed using the work of Harris and Goode (2004). Loyalty and Post-loyalty measures are adapted from the work of Rabbanee et al (2015). The expected switching intention items are created after a brainstorming with one marketing specialist and one specialist in community pharmacies, which resulted in three items. Table 2 shows the Variables of the factors:

Table 2. Measurements

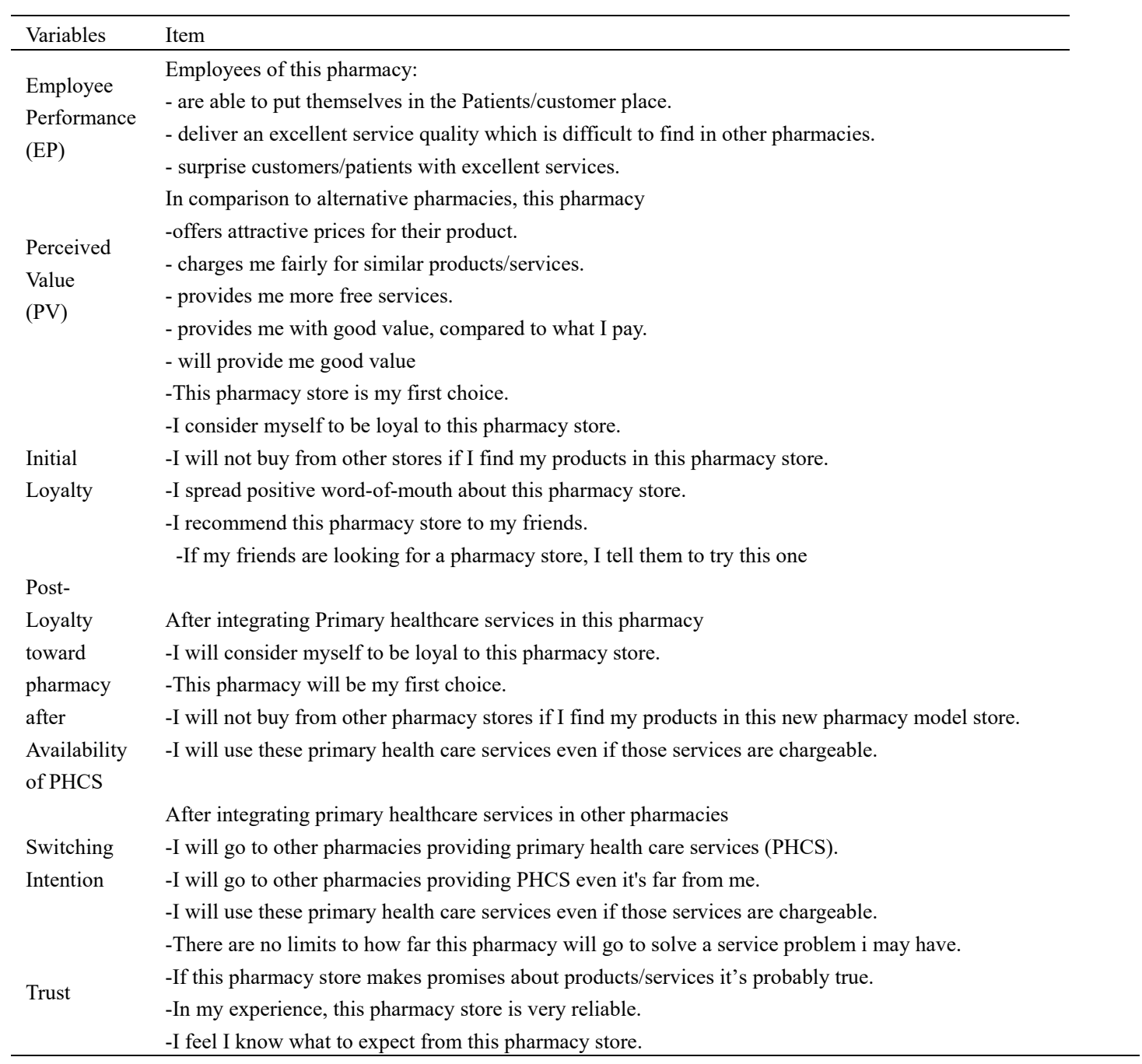

The method used to analyze this study's data consisted of starting by screening data and the dimensionality of scales via SPSS. The analysis relied in a second step on Smart PLS which helped checking the measurement model and the structural one.

\section{Results}

\subsection{Reliability and Validity Measurements}

Reliability is verified via Alpha of Cronbach and composite reliability (CR). Both satisfied the threshold 0.7 , as shown in the following Table 3. It shows also that all AVEs (average variance extracted) are above 0.5, which witnesses a good convergent validity. 
Table 3. Reliability measures

\begin{tabular}{lllll}
\hline & $\begin{array}{l}\text { Cronbach's } \\
\text { Alpha }\end{array}$ & Rho_A & $\begin{array}{l}\text { Composite } \\
\text { Reliability }\end{array}$ & $\begin{array}{l}\text { Average Variance Extracted } \\
\text { (AVE) }\end{array}$ \\
\hline EP & 0.757 & 0.776 & 0.860 & 0.673 \\
LOY 1 & 0.923 & 0.927 & 0.940 & 0.725 \\
PLO & 0.867 & 0.884 & 0.910 & 0.719 \\
Trust & 0.839 & 0.859 & 0.892 & 0.674 \\
PV & 0.891 & 0.896 & 0.920 & 0.698 \\
Switching & 0.730 & 0.765 & 0.842 & 0.640 \\
intention & & & & \\
\hline
\end{tabular}

The measures show also a good the discriminant validity, as the cross-loading matrix table (Table 4), proves that all used items loaded higher values, in association with their correspondent construct in comparison to those with other constructs.

Table 4. Cross-loading matrix

\begin{tabular}{lllllll}
\hline & EP & LOY 1 & PLO & Trust & PV & $\begin{array}{c}\text { Switching } \\
\text { intention }\end{array}$ \\
\hline EP & 0.820 & & & & & \\
LOY 1 & 0.490 & 0.851 & & & & \\
PLO & 0.314 & 0.671 & 0.848 & & & \\
Trust & 0.527 & 0.697 & 0.533 & 0.821 & & \\
PV & 0.547 & 0.558 & 0.325 & 0.652 & 0.835 & \\
Switching intention & 0.114 & 0.239 & 0.371 & 0.180 & 0.128 & 0.800 \\
\hline
\end{tabular}

\subsection{Hypotheses Testing and Discussion}

In the following, Table 5 shows the path estimates and their correspondent $\mathrm{P}$ values.

Table 5. Path parameters and hypotheses

\begin{tabular}{lllll}
\hline & B & T & P Values & Hypothesis \\
\hline Employee Performance $->$ Initial Loyalty & 0.133 & 3.022 & 0.003 & H3 \\
Perceived value -> Initial Loyalty & 0.134 & 2.842 & 0.005 & $\mathrm{H} 4$ \\
Trust-> Initial Loyalty & 0.54 & 12.006 & 0.000 & $\mathrm{H} 5$ \\
Loyalty -> Post loyalty & 0.671 & 23.611 & 0.000 & $\mathrm{H} 1$ \\
Loyalty-> Post Switching intention & 0.050 & 4.802 & 0.000 & $\mathrm{H} 2$ \\
\hline
\end{tabular}

Employee Performance has a positive impact on the initial pharmacy loyalty before adopting of the PHCS $(\mathrm{p}=0.003<0.05, \mathrm{~B}=0.133, \mathrm{~T}=3.022)$. Thus, $\mathrm{H} 3$ is accepted.

This is partially in line with the findings of Rabbanee et al, (2015) and Wongleedee (2020), because they have tested the indirect impact on loyalty via perceived value and trust, while we verified the direct impact on loyalty.

This led us to raise question about the partial and total effects of employee performance on loyalty. In addition This continues the efforts of verifying the impact of interpersonal service quality in retailing settings (Baker et al., 2002; Goić et al.2021). Bitner (1992) has considered that the servicescape influences the interaction between employees and customers, which leads in turn to positive behaviors from both stakeholders. Baker et al (2002) has used the concept of interpersonal service quality as a factor influencing patronage intentions toward a retailer. We added this idea in the specific context of pharmacy retailing. Results agree with Rabbanee et al (2015) that 
employees play a key starring role in pharmacies. These frontline employees have delicate and critical tasks which combine expert health services with selling tasks.

Perceived value has a positive impact on the loyalty toward the initial pharmacy before the adopting of the PHCS $(\mathrm{p}=0.005<0.05, \mathrm{~B}=0.134, \mathrm{~T}=2.842)$. Therefore, $\mathrm{H} 4$ is accepted. This is in accordance with the results of prior studies in the services context (Castaldo et al., 2016; Sweeney et al., 1999; Molinillo et al, 2021; Garrouch, 2021a,b) and namely in the context of community pharmacies (Rabbanee et al, 2015; Wongleedee, 2020). Indeed, Our result confirm the findings of previous studies for which customers tend to repurchase from the provider who offers a higher value for the money spent (Molinillo et al, 2021). This applies in particular in the healthcare services (Worlu et al. 2016, Wu et al, 2016; Rabbanee et al, 2015) and in community pharmacies as shown by our findings.

Trust has a positive impact on the initial pharmacy Loyalty before the adopting of the PHCS ( $p=0.000, B=0.54$, $\mathrm{T}=12.006$ ). $\mathrm{H} 3$ is accepted. This is in accordance with the findings of Rabbanee et al, (2015) and Wongleedee (2020), who have verified the direct impact of trust on loyalty toward pharmacies.

The loyalty toward the new pharmacy model is positively influenced by loyalty before the adopting of the PHCS $(\mathrm{P}=0.000, \mathrm{~B}=0.671, \mathrm{~T}=23.611)$. Thus, $\mathrm{H} 4$ is accepted.

This a new result that has not been verified previous literature. It explanation stems from the fact that the introduction of a new service which is valued by customer will sustain and enhance the existent loyalty.

The loyalty toward the initial pharmacy before the adopting of the PHCS has a significant and positive impact on switching intention toward other pharmacies which integrate PHCS ( $\mathrm{P}=0.000, \mathrm{~B}=0.239, \mathrm{~T}=4.802)$. As we expected that this path is negative, $\mathrm{H} 2$ is rejected. This surprising result can be explained by the low importance of the loyalty contribution to the switching intention and a possibility to stay loyal to the initial community pharmacy and at the same time switch to other pharmacies providing PHCS when needed. This leads to think about the concept of the multi-loyalty (Felix, 2014).

In this study, we find that even if the customers have the loyalty toward their initial community pharmacy which had not adopted PHCS, they will switch to other community pharmacies offering PHCS. Thus, PHCS will be a competitive advantage if provided by pharmacies. The resulting structural model is exhibited as follows (figure 2):

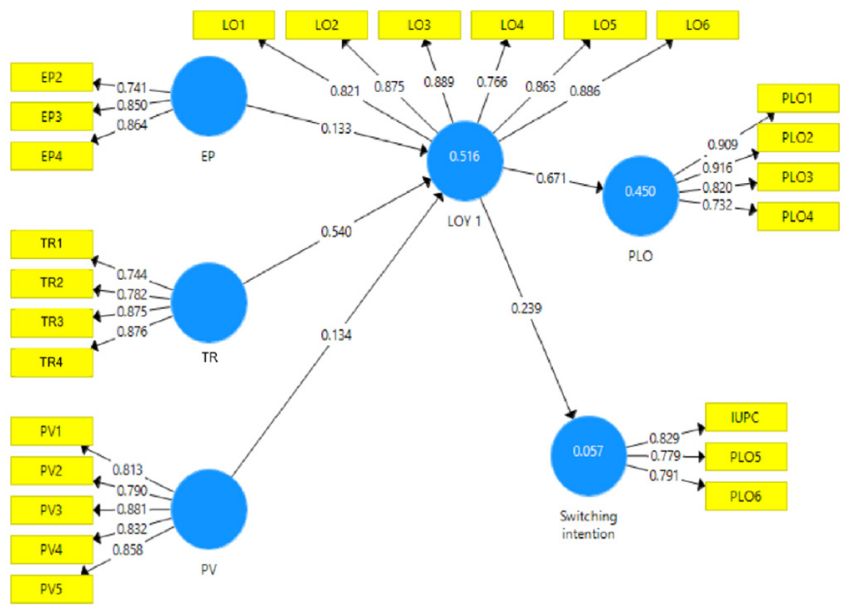

Figure 2. Structural Model

\section{Conclusion}

Community pharmacies play an essential role in the health of society and it would be interesting if they further help the healthcare systems by providing primary healthcare service to add value to their customers and to hamper the possible crowding in the public healthcare sector.

This research aims first to verify a model explaining the loyalty toward community pharmacies via three predictors: value, trust and employee performance. It further extends the available literature by trying to verify the speculative consequence of providing PHCS by what we call a new pharmacy model. This first attempt uses two possible reactions after a possible introduction of this service to a pharmacy to which customers are loyal: post-loyalty and Post-switching behavior. Results confirms our hypotheses expect the negative impact of initial loyalty on switching behavior. 
Those results highlight the importance of PHCS as a tool for having a competitive advantage among pharmacies. Indeed, its introduction will enhance and sustain the level of loyalty and even attract customers who are loyal to competitor in a way which makes them multi-loyal. Thus, we recommend pharmacies to prepare for introducing PHCS in a value-oriented strategy. First, they should study which PHCS types are the most trustful, valuable and required in their facilities by its customers. Second, they need to study the legal aspects of each PHCS service.

This research's limitations are mainly relative to the hypothetical existence of the pharmacies integrating PHCS in Saudi Arabia. We just made people imagine two situations: when the initial pharmacy included PHCS and when other pharmacies include these service.

Thus, the research is not an evidence base one, it proposes just the idea to be treated empirically in pharmacy settings that really include PHCS or using an experimental approach.

Thus, we propose to use an experimental approach in future research. Another limit is based on the fact that we did not precise which type of PHCS would have a higher loyalty impact. This can be highlighted also in the experimental approach proposed as a future study.

\section{References}

AlRefaie, A. (2015). Effects of human resource management on hotel performance using structural equation modeling. Computers in Human Behavior, 43, 293-303. https://doi.org/10.1016/j.chb.2014.11.016

Castaldo, S., Grosso, M., Mallarini, E., \& Rindone, M. (2016). The missing path to gain customers loyalty in pharmacy retail: The role of the store in developing satisfaction and trust. Research in Social and Administrative Pharmacy, 12(5), 699-712. https://doi.org/10.1016/j.sapharm.2015.10.001

Dwivedi, A. (2015). A higher-order model of consumer brand engagement and its impact on loyalty intentions. Journal of Retailing and Consumer Services, 24, 100-109. https://doi.org/10.1016/j.jretconser.2015.02.007

Fathelrahman, A. I., Ibrahim, M. I. M., \& Wertheimer, A. I. (2016). Pharmacy Practice in Developing Countries: Achievements and Challenges. Pharmacy Practice in Developing Countries: Achievements and Challenges (pp. 1-475). Elsevier Inc. https://doi.org/10.1016/C2014-0-00894-5

Felix, R. (2014). Multi-brand loyalty: when one brand is not enough. Qualitative Market Research, 17(4), 464480. https://doi.org/10.1108/QMR-11-2012-0053

Garrouch, K., \& Timoulali, E. H. (2020). Mobile Shopping Intentions: Do trustworthiness and culture Matter? Journal of Distribution Science, 18(11), 69-78. https://doi.org/10.15722/JDS.18.11.202011.69

Garrouch, K. (2021a). Does the reputation of the provider matter? A model explaining the continuance intention of mobile wallet applications. Journal of Decision Systems. https://doi.org/10.1080/12460125.2020.187026

Garrouch, K. F. (2021b). Explaining the comparative perception of e-payment: role of e-shopping value, e-payment benefits and Islamic compliance. Journal of Islamic Marketing. https://doi.org/10.1108/JIMA-08-2020-0240

Garrouch, K., Mzoughi, M. N., \& Tritar, N. (2012). Impact of the perceived crowding, emotions and perceived values on the return intention: evidence from Tunisia. International Journal of Business and Emerging Markets, 4(2), 143. https://doi.org/10.1504/ijbem.2012.046238

Garrouch, K., MZOUGHI, M. N., \& Chaieb, S. (2020). An integrative model of the impact of the store environment in supermarkets and hypermarkets. Recherches En Sciences de Gestion, (138), 185-212.

Graciola, A. P., De Toni, D., Milan, G. S., \& Eberle, L. (2020). Mediated-moderated effects: High and low store image, brand awareness, perceived value from mini and supermarkets retail stores. Journal of Retailing and Consumer Services, 55. https://doi.org/10.1016/j.jretconser.2020.102117

Gupta, K. S., \& Rokade, V. (2016). Importance of quality in health care sector: A review. Journal of Health Management, 18(1), 84-94. https://doi.org/10.1177/0972063415625527

Gwinner, K. P., Gremler, D. D., \& Bitner, M. J. (1998). Relational benefits in services industries: The customer's perspective. Journal of the Academy of Marketing Science, 26(2), 101-114. https://doi.org/10.1177/0092070398262002

Jung, J. H., Yoo, J. J., \& Arnold, T. J. (2021), The influence of a retail store manager in developing frontline employee brand relationship, service performance and customer loyalty. Journal of Business Research, 122, 362-372. https://doi.org/10.1016/j.jbusres.2020.09.010

Lee, C. (2021). Informational Justice, Cognitive Trust, and Satisfaction: Purchasers' Perspective of Healthcare Distribution Market. 유통과학연구, 19(2), 5-14. https://doi.org/10.15722/JDS.19.2.202102.5 
Martínez-Mardones, F., Ahumada-CCanale, A., Gonzalez-Machuca, L., \& Plaza-Plaza, J. (2020). Primary health care pharmacists and vision for community pharmacy and pharmacists in Chile. Pharmacy Pract (Granada), 18(3), 21-42. http://dx.doi.org/10.18549/pharmpract.2020.3.2142

Mayer, R. C., Davis, J. H., \& Schoorman, F. D. (1995). An integrative Model of Oorganizational Trust. Academy of Management Review, 20(3), 709-734. https://doi.org/10.5465/amr.1995.9508080335

Meesala, A., \& Paul, J. (2018). Service quality, consumer satisfaction and loyalty in hospitals: Thinking for the future. Journal of Retailing and Consumer Services, 40, 261-269. https://doi.org/10.1016/j.jretconser.2016.10.011

Molinillo, S., Aguilar-Illescas, R., Anaya-Sánchez, R., \& Liébana-Cabanillas, F. (2021). Social commerce website design, perceived value and loyalty behavior intentions: The moderating roles of gender, age and frequency of use. Journal of Retailing and Consumer Services. https://doi.org/10.1016/j.jretconser.2020.102404

Morgan, R. M., \& Hunt, S. D. (1994). The Commitment-Trust Theory of Relationship Marketing. Journal of Marketing, 58(3), 20-38. https://doi.org/10.1177/002224299405800302

Oliver, R. L. (1999). Whence consumer loyalty? Journal of Marketing, 63, 33-44. https://doi.org/10.2307/1252099

Perepelkin, J., \& Di Zhang, D. (2011). Brand personality and customer trust in community pharmacies, International Journal of Pharmaceutical and Healthcare Marketing, 5(3), 175-193. https://doi.org/10.1108/17506121111172194

Quoquab, A., Mohammad, J., Norjaya, M. Y., Nor, L. A. (2018). Antecedents ofswitching intention in the mobile telecommunications industry: A partial least square approach. Asia Pacific Journal of Marketing and Logistics. https://doi.org/10.1108/APJML-06-2017-0121

Rabbanee, F. K., Burford, O., \& Ramaseshan, B. (2015), Does employee performance affect customer loyalty in pharmacy services? Journal of Service Theory and Practice, 25(6), 725-743. https://doi.org/10.1108/JSTP06-2014-0126

Salanova, M., Agut, S., \& Peiro', J. M. (2005). Linking organizational resources and work engagement to employee performance and customer loyalty: the mediation of service climate. Journal of Applied Psychology, 90(6), 1217-1227. https://doi.org/10.1037/0021-9010.90.6.1217

Shawky, S., Kubacki, K., Dietrich, T., \& Weaven, S. (2020). A dynamic framework for managing customer engagement on social media. Journal of Business Research, 121, 567-577. https://doi.org/10.1016/j.jbusres.2020.03.030

Song, Y., Guo, S., \& Zhang, M. (2019). Assessing customers' perceived value of the anti-haze cosmetics under haze pollution. Science of the Total Environment, 685, 753-762. https://doi.org/10.1016/j.scitotenv.2019.06.254

Sweeney, J. C., Soutar, G. N., \& Johnson, L. W. (1999). The role of perceived risk in the quality-value relationship: A study in a retail environment. Journal of Retailing, 75(1), 77-105. https://doi.org/10.1016/S00224359(99)80005-0

Thaichon, P., \& Jebarajakirthy, C. (2016), Evaluating specific service quality aspects which impact on customers' behavioral loyalty in high-tech internet services. Asia Pacific Journal of Marketing and Logistics, 28(1), 141159. https://doi.org/10.1108/APJML-02-2015-0027

Torres, E., Vasquez-Parraga, A. Z., \& Barra, C. (2009). The path of patient loyalty and the role of doctor reputation. Health Marketing Quarterly, 26(3), 183-197. https://doi.org/10.1080/07359680903263565

Urick, B. Y., \& Urmie, J. M. (2019). Framework for assessing pharmacy value. Research in Social and Administrative Pharmacy, 15, 1326-1337. https://doi.org/10.1016/j.sapharm.2018.12.008

Wang, Z., Singh, S. N., Li, Y. J., Mishra, S., Ambrose, M., \& Biernat, M. (2017). Effects of employees' positive affective displays on customer loyalty intentions: An emotions as- social-information perspective. Academy of Management Journal, 60(1), 109-129. https://doi.org/10.5465/amj.2014.0367

Wongleedee, K. (2020). Role of customer loyalty on employee performance and productivity in pharmacy business in Thailand. Systematic Reviews in Pharmacy, 11(2), 631-641. https://doi.org/10.5530/srp.2020.2.9

Woodruff, R. B. (nd.). Customer value: The next source for competitive advantage. Journal of the Academy of Marketing Science, 25, 139. https://doi.org/10.1007/BF02894350

Worlu, R., Kehinde, O. J., \& Borishade, T. T. (2016). Effective customer experience management in health-care 
sector of Nigeria: A conceptual model. International Journal of Pharmaceutical and Healthcare Marketing, 10(4), 449-466. https://doi.org/10.1108/IJPHM-12-2015-0059

Wu, H. C., Li, T., \& Li, M. Y. (2016). A study of behavioral intentions, patient satisfaction, perceived value, patient trust and experiential quality for medical tourists. Journal of Quality Assurance in Hospitality \& Tourism, 17(2), 114-150. https://doi.org/10.1080/1528008X.2015.1042621

Xue, J., Liang, X., Xie, T., \& Wang, H. (2020). See now, act now: how to interact with customers to enhance social commerce engagement? Information. Management. 57. https://doi.org/ 10.1016/j.im.2020.103324

Yang, Z., \& Peterson, R. T. (2004). Customer perceived value, satisfaction, and loyalty: the roleof switching costs. Psychology and Marketing, 21(10), 799-822. https://doi.org/10.1002/mar.20030

Zeithaml, V. A. (1988). Consumer Perceptions of Price, Quality, and Value: A Means-End Model and Synthesis of Evidence. Journal of Marketing, 52(3), 2-22. https://doi.org/10.1177/002224298805200302

Zeithaml, V. A., Berry, L. L., \& Parasuraman, A. (1996). The behavioral consequences of service quality. Journal of Marketing, 60, 31-46. https://doi.org/10.2307/1251929

Bitner, M., J. (1992). Servicescapes: the impact of physical surroundings on customers and employers. Journal of Marketing, 56(2), 57-72.

Goić, M., Levenier, C., \& Montoya, R. (2021). Drivers of customer satisfaction in the grocery retail industry: A longitudinal analysis across store formats. Journal of Retailing and Consumer Services, 60, 102505. https://doi.org/10.1016/j.jretconser.2021.102505

Baker J, Parasuraman, A., Grewal, D., \& Voss, G. B. (2002). The Influence of Multiple Store Environment Cues on Perceived Merchandise Value and Patronage Intentions. Journal of Marketing, 66(2), 120-141. https://doi.org/10.1509/jmkg.66.2.120.18470

Bitner, M. J. (1992). Servicescapes: The Impact of Physical Surroundings on Customers and Employees. Journal of Marketing, 56(2), 57-71. https://doi.org/10.1177/002224299205600205

\section{Copyrights}

Copyright for this article is retained by the author(s), with first publication rights granted to the journal.

This is an open-access article distributed under the terms and conditions of the Creative Commons Attribution license (http://creativecommons.org/licenses/by/4.0/). 